\title{
Tunnel Behaviour Caused by Basement Excavation in Clay
}

\author{
Huasheng Sun $\mathbb{D}^{D}$, Jihua Zhang $\mathbb{D}$, Guodong Zhao $\mathbb{D}$, and Hao Wang $\mathbb{D}$
}

Huaiyin Institute of Technology, 89 North Beijing Road, Huai'an 223001, China

Correspondence should be addressed to Jihua Zhang; zhangjh84@hyit.edu.cn

Received 18 January 2021; Revised 21 February 2021; Accepted 11 March 2021; Published 30 March 2021

Academic Editor: Yi Xue

Copyright () 2021 Huasheng Sun et al. This is an open access article distributed under the Creative Commons Attribution License, which permits unrestricted use, distribution, and reproduction in any medium, provided the original work is properly cited.

\begin{abstract}
Many researchers have investigated the effect of basement excavation on tunnel deformation. However, the influence of consolidation on the interaction of basement-tunnel-soil is rarely considered or systematically studied in clay. In this study, three-dimensional coupled-consolidation finite element analyses were conducted to investigate the effect of consolidation on the tunnel response to excavation. An advanced nonlinear constitutive model was adopted, and numerical parametric investigations were conducted to study the effect of the excavation depth, tunnel stiffness, soil permeability coefficient, and consolidation time on the tunnel response. The results revealed that the basement excavation led to stress release, which caused tunnel heave. Owing to the dissipation of excess negative pore water pressure, the tunnel heave further increased to become approximately twice as large compared with that observed when the foundation pit excavation had just been completed. As the consolidation time increased, the longitudinal tunnel heave and tunnel diameter change caused by the foundation pit excavation gradually increased, but the growth rate was slower down. When the consolidation time changed from 50 days to 150 days, the maximum tunnel heave at the crown and the maximum tunnel diameter change increased by 1.18 and 1.48 times, respectively. The soil's permeability coefficient did not have a significant effect on the tunnel heave at the crown nor on the tunnel diameter change. The results obtained by this study are expected to be useful as an engineering reference for the analysis of soil structure problems in clay.
\end{abstract}

\section{Introduction}

With the further progress of urbanization, the foundation pit engineering appears constantly, most of which are located in structures and densely populated areas. In current foundation pit engineering design, not only the effect of adjacent structures on the foundation pit but also the effect of foundation pit excavation on adjacent structures should be considered. The former is mainly to ensure that reasonable measures are taken to ensure the safety of foundation pit excavation and foundation construction, while the latter is to consider the excessive deformation of adjacent buildings caused by the excessive deformation of foundation pit, thus affecting the safety of structures. If appropriate measures are not taken, the adjacent structures will be damaged, causing serious economic losses and huge social impact. As a major engineering problem in urban underground space construction, it is essential to predict and evaluate the interaction between foundation pit excavation and adjacent structures.

The deformation of adjacent tunnels as a result of basement excavation is such a typical problem in this kind of major engineering problems. To investigate the effect of tunnels due to a nearby basement excavation, numerous studies have been conducted using field tests [1-5], centrifuge model tests [6-10], and analytical and numerical methods [11-27].

Burford [1] reported that the excavation of the large basement of the Shell Centre in London Clay resulted in an upward displacement between $20 \mathrm{~mm}$ and $30 \mathrm{~mm}$ for the underlying Bakerloo line tunnel. After 27 years, the maximum uplift measured under the basement of the southbound Bakerloo tunnel was $50 \mathrm{~mm}$, while that of the northbound tunnel was $41 \mathrm{~mm}$. It is shown that the release of overburden pressure will lead to long-term uplift of a tunnel in London clay. Shi et al. [10] carried out three-dimensional centrifuge tests to investigate tunnel responses due to overlying 
basement excavation in lightly (overconsolidation ratio $(\mathrm{OCR})=1.7)$ and heavily overconsolidated $(\mathrm{OCR}=6.0)$ kaolin clays. It is found that special attention should be paid to long-term rather than short-term tunnel responses.

However, most previous studies investigating the tunnel deformation caused by basement excavation mainly focused on the short-term tunnel response [2, 4-6, 8, 9, 11, 14-27]. The field monitoring of a tunnel affected by foundation pit excavation in clay revealed that the long-term heave of the tunnel in clay is very large, and the time required to reach the steady state is very long [1]. Thus, it seems that the subway tunnel response on clay ground is highly dependent on time. Therefore, in the analysis of the existing tunnel response in clay, it is important to consider the short-term response systematically from the foundation pit excavation construction period and the long-term response after the construction is completed.

Prediction of tunnel response induced by excavation is becoming one of the major tasks for geotechnical engineers. The use of the numerical method to analyse the interaction between excavation and the existing tunnel is frequent [11, $13-20,22,23,28,29]$. It is well known that a soil model in the numerical method should capture the state-, strain-, and path-dependent soil stiffness even at small strains and path- and state-dependent soil strength. In addition, the consolidation characteristics should be considered in clay. In order to investigate the influence of a basement excavation on the tunnel behaviour in dry sand precisely, $\mathrm{Ng}$ et al. [8] carried out two centrifuge model tests to investigate this issue. Several numerical analyses based on these centrifuge model tests were conducted by adopting the hypoplasticity model for sand, and it was found that the hypoplasticity model can more effectively capture the soil behaviour compared with the previously reported centrifuge model test $[9,16,18,19]$. Mašín and Herle [30] developed a basic hypoplastic model to predict the clay behaviour at medium to large strain levels. To account for strain-dependent and path-dependent soil stiffness at small strains, Mašín [31] improved the basic hypoplastic model by incorporating the concept of the intergranular strain [32]. The improved model was used by Najser et al. [33] and the computed ground deformations agree with the measured results. However, numerical simulation considering the state-, strain-, and path-dependent soil stiffness even at small strains, the path- and state-dependent soil strength, and the consolidation characteristics of soil has not been reported in literatures to investigate the interaction of foundation pit excavation and existing tunnel.

Considering the abovementioned issues, the aim of this paper was to investigate the tunnel behaviour and elucidate the internal law and mechanism of tunnel deformation resulting from basement excavation in clay. To this end, three-dimensional coupled-consolidation numerical analyses using the clay hypoplasticity model were carried out to simulate the long-term response of a tunnel subjected to basement excavation in clay. Numerical parametric investigations were also conducted to study the influence of the basement excavation depth, soil and tunnel property, and the consolidation effect on the tunnel response.

\section{Material and Methods}

The software ABAQUS (Version 6.17; ABAQUS, Inc.) was adopted to conduct numerical analyses, wherein the hypoplastic model of clay with user-defined subroutine was established by Mašín [34, 35].

2.1. Finite Element Model. The finite element mesh shown in Figure 1 was constructed on the basis of the model test reported by $\mathrm{Ng}$ et al. [8]. In this model, the finite element mesh dimension was $18 \mathrm{~m}$ in length, $18 \mathrm{~m}$ in width, and $9 \mathrm{~m}$ in depth in the prototype. The tunnel diameter was $6 \mathrm{~m}$ in the prototype. The other dimensions of basement excavation and retaining wall were the same as that in the model test. It should be noted that the centrifuge model tests were conducted in sand but the finite element was carried out in clay. For the boundary condition, roller supports were adopted at the vertical surfaces and pin supports were adopted at the bottom of the model. Soil-water coupling analysis theory was adopted. The groundwater level was set on the model top, and the bottom of the model was set as an undrained boundary. To simulate the recharge of external groundwater during the foundation pit excavation, the pore pressure at the side boundaries of the model was set as hydrostatic pressure and remained unchanged throughout the analysis process. The top surface of the model was set as a free drainage boundary. The element types of the soil, retaining wall, and tunnel were C3D8P, C3D8, and S4, respectively. Interface elements were used at the soil-tunnel and at the soil-retaining wall interfaces. The setting method can be referred to document reported by $\mathrm{Ng}$ et al. [16].

2.2. Constitutive Model and Related Parameters. It is essential to adopt a constitutive model which can simulate the soil behaviour varying with strain from small to large levels. A clay hypoplastic model proposed by Mašín [31] was used to predict the behaviour of the clay. The original model requires five parameters: $\varphi_{c}^{\prime}, \mathrm{N}, \lambda^{*}, \kappa^{*}$, and $r$ to predict the behaviour of clay from medium to large strain levels. The other five parameters, namely, $R, m_{\mathrm{T}}, m_{\mathrm{R}}, \beta_{r}$, and $\chi$ are required to predict the soil response in the small-strain range. The physical meaning of these parameters was shown in Table 1. Mašín [36] reported the calibration of the parameters for London Clay in the hypoplastic clay model. Table 1 summarizes the parameters for London Clay used in this study. The tunnel and retaining wall were simulated as a linear elastic material. Both their Young's modulus and Poisson's ratio are $70 \mathrm{GPa}$ and 0.2 , respectively.

2.3. Numerical Simulation Process. The finite element simulation process before soil consolidation is essentially the same as the centrifugal model test process. The tunnel and retaining structure were simulated using the "wished in place" method, which assumes that the tunnel and retaining structure already exist before the foundation pit excavation. Gravity was applied in the way of the physical force, and the analysis is based on the excess pore pressure. The simulation process is summarized as follows: 


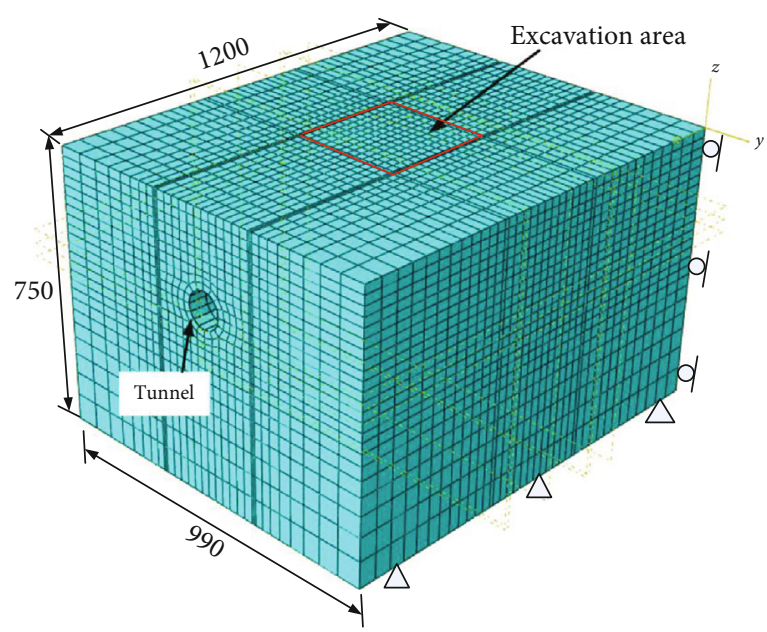

(a)

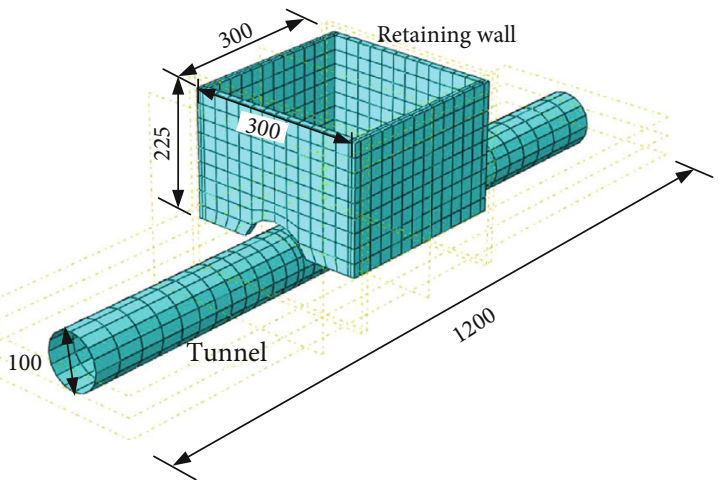

(b)

FIgure 1: (a) Finite element model and (b) retaining wall and tunnel (all dimensions in model scale, unit: $\mathrm{mm}$ ).

Table 1: Parameters of London Clay in the clay hypoplastic model [36].

\begin{tabular}{lcc}
\hline Parameters & Physical meaning & Values \\
\hline$N$ & Control the position of the isotropic normal compression line & 1.375 \\
$\lambda^{*}$ & Control the slope of the isotropic normal compression line & 0.11 \\
$\kappa^{*}$ & Control the slope of the isotropic unloading line & 0.016 \\
$\varphi_{c}^{\prime}$ & The critical state friction angle & $22.6^{\circ}$ \\
$r$ & Control the shear stiffness & 0.4 \\
$m_{\mathrm{R}}$ & Parameter controlling the initial (very-small-strain) shear \\
$m_{\mathrm{T}}$ & Modulus upon $180^{\circ}$ strain path reversal and in the initial loading & $1 \times 10^{-4}$ \\
$R$ & Parameter controlling the initial shear modulus upon $90^{\circ}$ & 4.5 \\
$\beta_{r}$ & Strain path reversal & 4.5 \\
$\chi$ & The size of the elastic range (in the strain space) & 0.2 \\
\hline
\end{tabular}

(1) The initial stress field of the soil is established under the $1 \mathrm{~g}$ condition. The initial stress in the tunnel and retaining structure is the same as that of the surrounding soil

(2) Gradually increase the acceleration of gravity until $60 \mathrm{~g}$

(3) Simulate the excavation process using the birth-death element method and complete the excavation in three steps of $3 \mathrm{~m}$ each

(4) After the basement excavation is completed, the consolidation time of 50,100,150, and 200 days is set to investigate the effect of the surrounding soil's consolidation on the tunnel deformation

\section{Interpretation of Calculated Results}

3.1. Tunnel Heave along the Tunnel Axis. Figure 2 shows the calculated tunnel heave resulting from the basement excava- tion and subsequent consolidation for 100 days. With the increase of foundation pit excavation depth, the tunnel heave increases gradually. After the foundation pit excavation, the calculated tunnel heave was $0.020 \% H_{\mathrm{e}}$ under the basement centre, wherein, $H_{\mathrm{e}}$ is the basement depth. After consolidation for 100 days, the calculated maximum value of the tunnel heave was $0.041 \% H_{\mathrm{e}}$. The measured maximum tunnel heave given by $\mathrm{Ng}$ et al. [8] is $0.023 \% H_{\mathrm{e}}, 0.051 \% H_{\mathrm{e}}$, and $0.074 \% H_{\mathrm{e}}$ for each excavation depth $3 \mathrm{~m}, 6 \mathrm{~m}$, and $9 \mathrm{~m}$, respectively. This is because different soil media are used in each case although using the same size of the model equipment. By comparing the tunnel heave calculated for different stages in clay, it is found that the maximum tunnel heave as a result of stress relief after immediately excavation was approximately half of the magnitude after consolidation for 100 days. Thus, it is concluded that the consolidation effect on the tunnel heave is significant. Moreover, the effect of consolidation on the tunnel heave is approximately the same as when the basement construction has just been completed, which is analogous to the case reported by Burford [1] and 


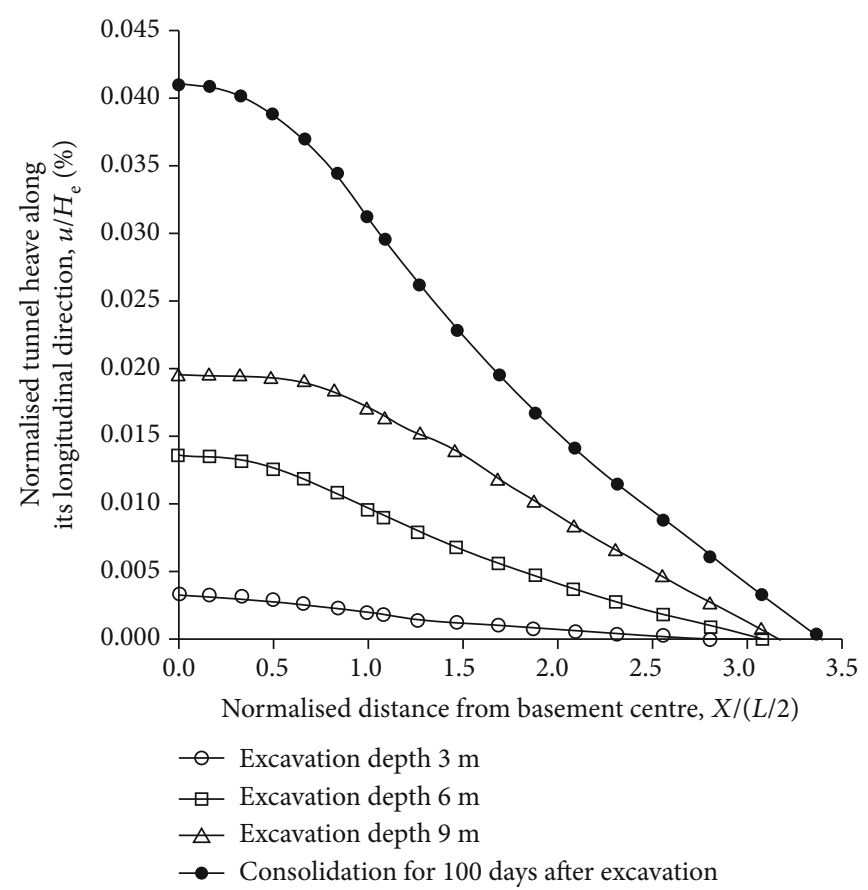

Figure 2: Normalised tunnel displacement along tunnel axis.

Shi et al. [10]. This enlightens us that, in engineering practice, it is necessary to pay close attention to the long-term influence of foundation pit excavation on tunnel displacement in clay. Once the foundation pit is exposed for a long time or the superstructure construction is too long, corresponding measures should be taken to control the tunnel displacement to prevent the tunnel lining from being damaged due to excessive deformation.

3.2. Vertical Stress Change in Soil at Tunnel Crown. To deeply understand the mechanism of the consolidation effect's influence on the tunnel's longitudinal deformation, the results for the vertical stress change at the longitudinal tunnel crown are shown in Figure 3. As can be seen, when the foundation pit excavation was completed, the vertical stress of the soil at the tunnel crown decreased owing to the stress release, and the maximum variation was approximately $-8 \mathrm{kPa}$. The vertical stress variation in the excavated area of the foundation pit was approximately nonlinear. Because of the stress concentration, the soil stress at the bottom of the retaining structure rapidly increased, the maximum value was approximately $22 \mathrm{kPa}$, and the stress variation exceeded the maximum allowable stress change value specified by the $\mathrm{BD}$ [37] $( \pm 20 \mathrm{kPa})$. The soil stress change after the retaining structure sharply decreased and was within $20 \mathrm{kPa}$. Because of the excavation unloading, a large amount of soil stress was released and the tunnel moved upward, while the soil behind the retaining structure moved into the pit, and the soil behind the wall settled. The friction force generated by the relative movement of the soil and the retaining structure prevented the upward movement of the tunnel behind the wall, which resulted in tunnel uplift. After 100 days of excavation, the effective stress at the top of the tunnel and directly below

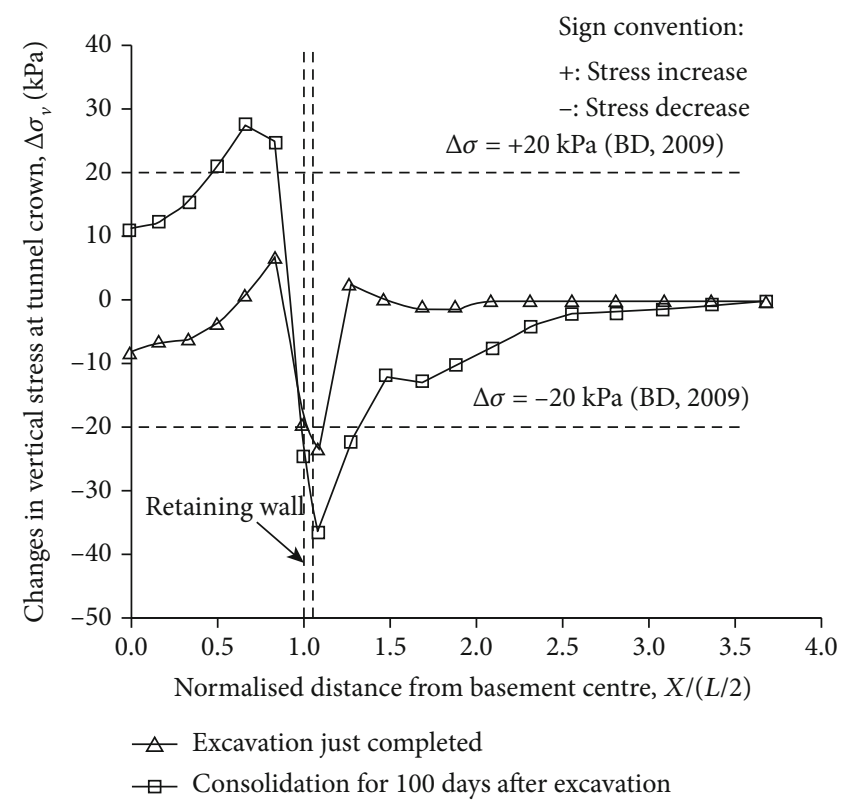

FIgURe 3: Vertical stress change in soil at tunnel crown.

the centre of the foundation pit increased by $11 \mathrm{kPa}$ relative to the initial value. According to the principle of effective stress, with the dissipation of excess pore water pressure, the effective stress in the soil at the tunnel crown gradually increased. This is consistent with existing observation data for foundation pit excavation in clay $[38,39]$.

3.3. Tunnel Deformation in the Transverse Direction. Figure 4 shows the variation of the tunnel diameter change with the 


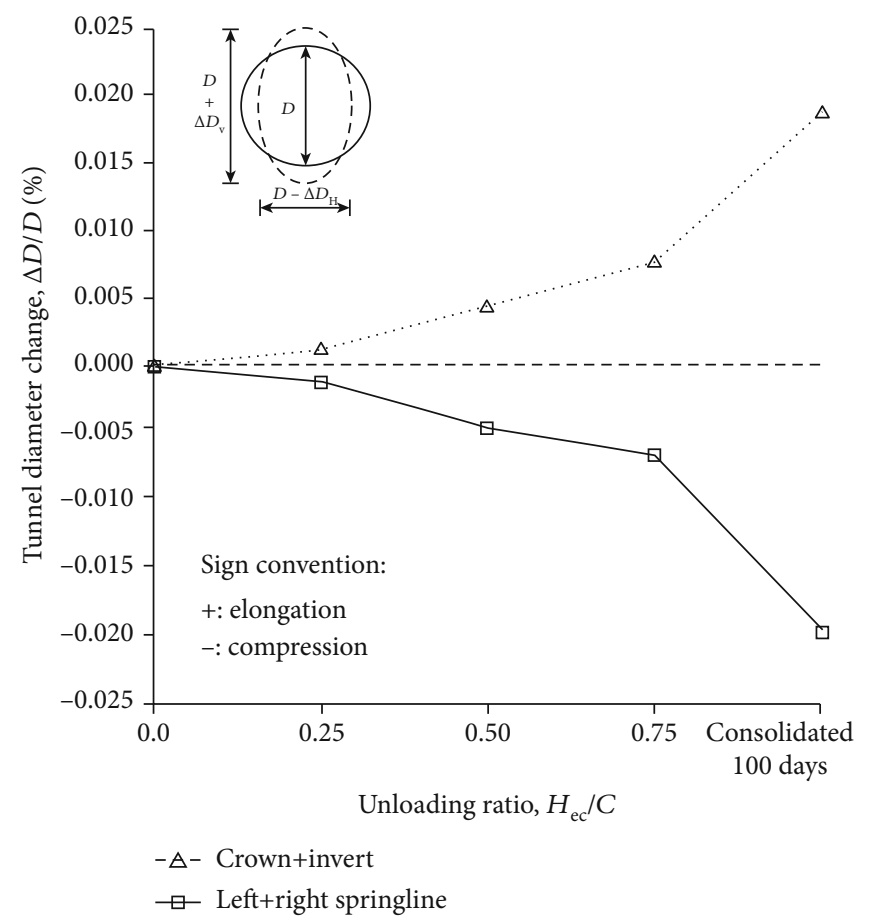

Figure 4: Tunnel diameter change in transverse direction in clay.

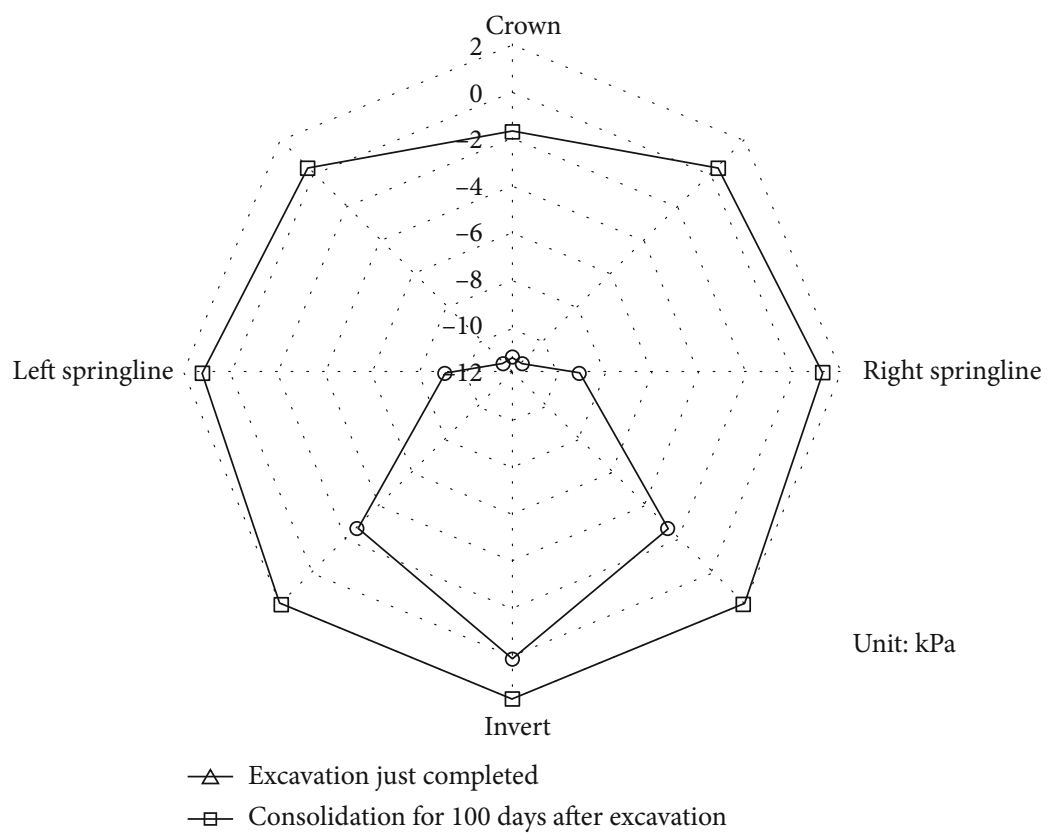

FIGURE 5: Earth pressure change around tunnel lining in clay.

excavation unloading ratio and consolidation time. The unloading ratio is defined as the ratio of the excavation depth of the foundation pit to the cover-depth of the tunnel. The positive value of the ordinate indicates the stretching of the tunnel diameter, while the negative value indicates the compression of the tunnel diameter. As can be seen in the figure, the excavation unloading of the foundation pit directly above the tunnel led to the vertical extension and horizontal com- pression of the tunnel. As the unloading ratio increased, the vertical diameter of the tunnel gradually elongated and the horizontal diameter gradually compressed. When the basement excavation was completed, the vertical elongation $\left(\Delta D_{V}\right)$ of the tunnel was $0.008 \% D$ and horizontal compression $\left(\Delta D_{H}\right)$ of the tunnel was $0.007 \% D(D$ is the tunnel diameter). After 100 days of consolidation following the excavation, the vertical elongation $\left(\Delta D_{V}\right)$ and horizontal 


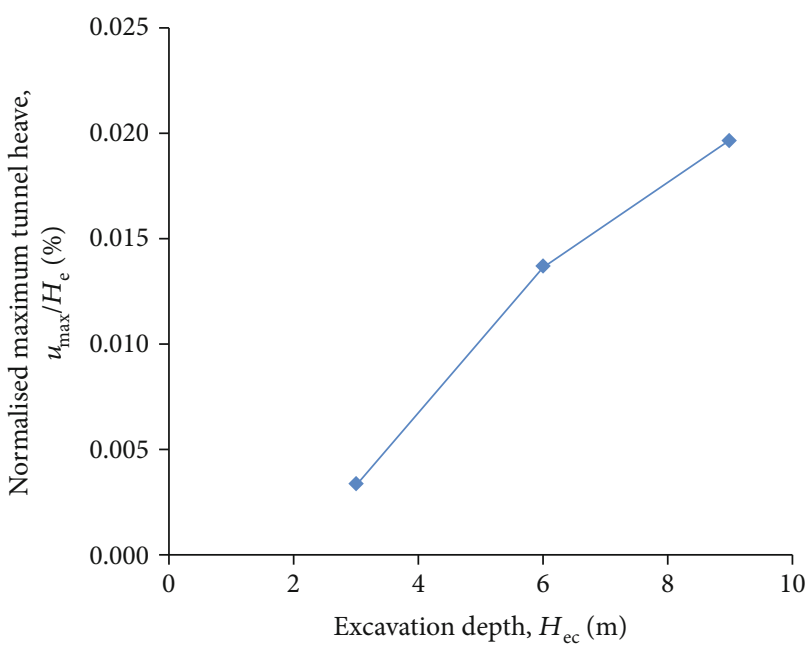

FIgURE 6: Tunnel heave as a result of different basement excavation depth in clay.

compression $\left(\Delta D_{H}\right)$ of the tunnel were $0.019 \% D$ and $0.020 \% D$, respectively, both of which are approximately twice as large as that observed when the foundation pit was completed. According to the BTS [40], the allowable maximum value of tunnel deformation $\left(\left(\Delta D_{V}+\Delta D_{H}\right) / 2\right)$ is $2 \%$. Therefore, the tunnel deformation is within the allowable range.

3.4. Earth Pressure Change around Tunnel Lining. Figure 5 shows the change of earth pressure in tunnel's cross-section after the foundation pit excavation. The tunnel's crosssection was located directly below the basement's excavation centre. Because of the symmetry, the earth pressure around the tunnel was symmetrically distributed. The stress release above the arch line of the tunnel was greater than that of the soil below the arch line. The vertical stress release of the soil around the tunnel was greater than that in the horizontal direction. Therefore, the tunnel diameter was vertically stretched and horizontally compressed, as shown in Figure 4. Additionally, as shown in Figure 5, the earth pressure above the tunnel springlines changed more than that below the springlines, which resulted in overall tunnel uplift. After 100 days of consolidation following the foundation pit excavation, as a result of the dissipation of excess negative pore water pressure, the earth pressure acting on the tunnel crown increased while the change at the invert was small, which resulted in the further increase of tunnel lining deformation, as shown in Figure 4.

\section{Parametric Investigation}

4.1. Effect of Basement Excavation Depth. Figure 6 shows the effect of the basement excavation depth on the maximum tunnel displacement at the crown in clay. The basement had variable depth of $3 \mathrm{~m}, 6 \mathrm{~m}$, and $9 \mathrm{~m}$. The computed maximum tunnel displacement was $0.003 \% H_{\mathrm{e}}, 0.013 \% \mathrm{H}_{\mathrm{e}}$, and $0.020 \% H_{e}$, respectively. It is found that the maximum tunnel displacement in the longitudinal direction increased gradu- ally as the basement depth increased; however, the growth rate slowed down.

4.2. Effect of Tunnel Lining Stiffness. Figure 7 shows the effect of the tunnel lining stiffness on the distribution of tunnel heave along tunnel axis and the maximum tunnel heave in clay. Considering that the tunnel material is unchanged, for convenience, the bending rigidity of the tunnel $\left(E_{\mathrm{t}} I_{\mathrm{t}}\right)$ is replaced by the elastic modulus of the tunnel $\left(E_{t}\right)$. As can be seen, the tunnel distribution shape was basically the same for different tunnel lining stiffness. The tunnel stiffness did not affect the main influence area caused by basement excavation. The maximum tunnel displacement decreased linearly with the logarithm of the tunnel lining stiffness.

4.3. Effect of Soil Permeability Coefficient. The effect of the soil permeability coefficient on the tunnel longitudinal heave is shown in Figure 8 . Let the soil permeability coefficient in the foundation model be $K_{0}=3.6 \times 10^{-6} \mathrm{~m} / \mathrm{s}$ and compare the other two different working conditions, that is, $K_{1}=$ $3.6 \times 10^{-5} \mathrm{~m} / \mathrm{s}$ and $K_{2}=3.6 \times 10^{-4} \mathrm{~m} / \mathrm{s}$. As illustrated in Figure 8 , the longitudinal uplift of the tunnel increased with the permeability coefficient. When the permeability coefficient of the basic model increased by 10 times and 100 times, the longitudinal uplift of the tunnel increased by $15 \%$ and $17 \%$, respectively. As can be seen, the soil permeability coefficient only has a small effect on the tunnel uplift deformation. When the permeability coefficient of the soil increased more than 10 times, the maximum tunnel heave underwent a minor change.

4.4. Effect of Soil Consolidation Time. Figure 9 illustrates the variation of the tunnel longitudinal heave with the consolidation time. After the foundation pit excavation was completed, the soil consolidation time was set to 50,100,150, and 200 days, respectively. Compared with the completion of the foundation pit excavation, the maximum uplift of the tunnel crown increased by $0.90,1.10,1.15$, and 1.18 times, respectively. As can be seen, the consolidation effect had a significant effect on the tunnel heave. As the consolidation time increased, the maximum uplift at the crown of the tunnel gradually increased, but the growth rate slowed down. Compared with 150 days of consolidation, the maximum tunnel uplift only changed by $2.6 \%$ for 200 days of consolidation. As can be seen, the consolidation can be considered to have completed 150 days after the foundation pit excavation.

Figure 10 illustrates the variation of tunnel diameter change in the cross-section with the consolidation time. With the increase of the unloading ratio, the vertical diameter of the tunnel gradually elongated and the horizontal diameter gradually compressed. After the foundation pit excavation was completed, the soil consolidation time was set to 50, 100 , and 150 days. Compared with the completion of the basement excavation, the maximum elongation of the tunnel cross-section lining increased by $1.10,1.44$, and 1.48 times, respectively. As can be seen, the consolidation effect had a significant effect on the deformation of the tunnel lining in the transverse direction. As the consolidation time increased, 


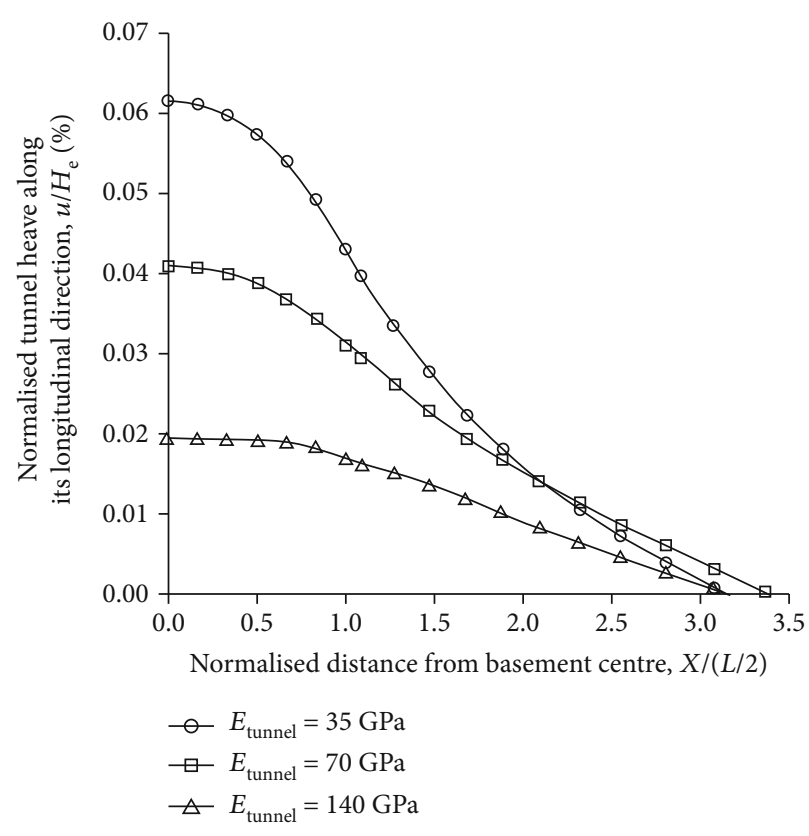

(a)

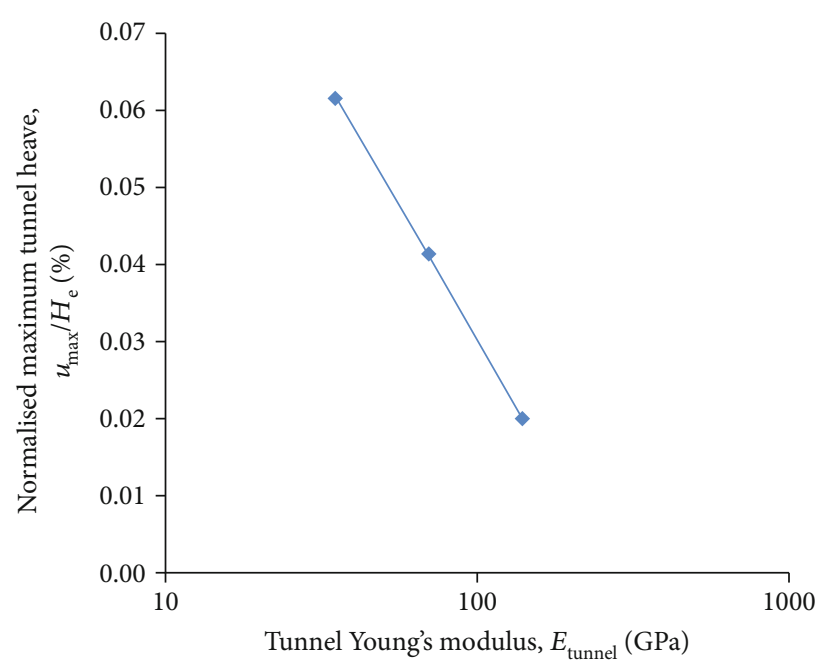

(b)

FIGURE 7: Influence of tunnel Young's modulus on (a) tunnel heave along its axis and (b) maximum tunnel displacement in clay.

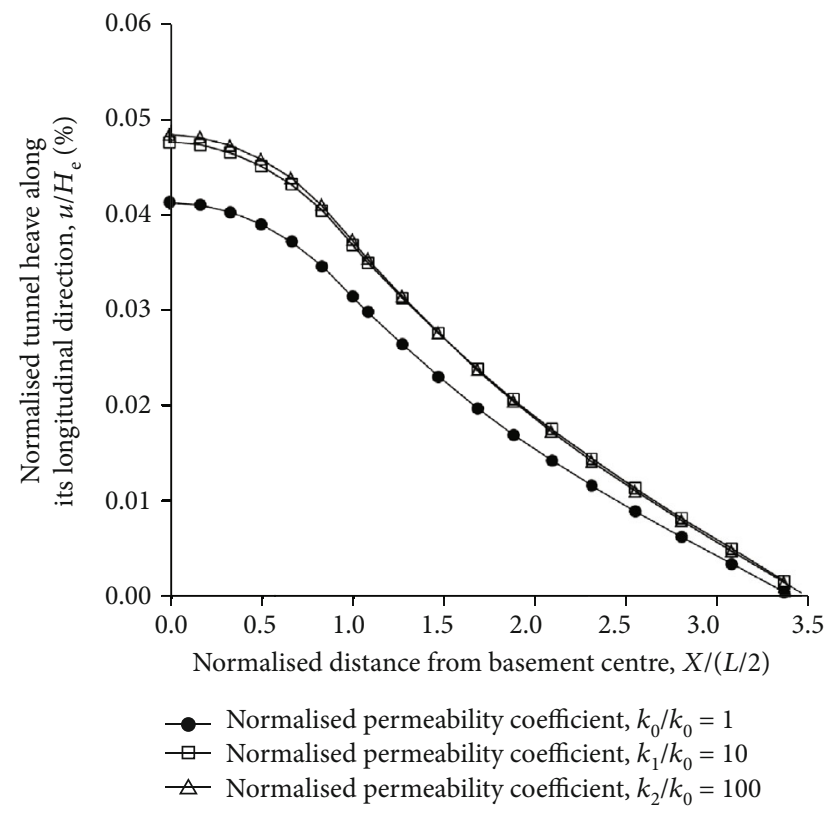

(a)

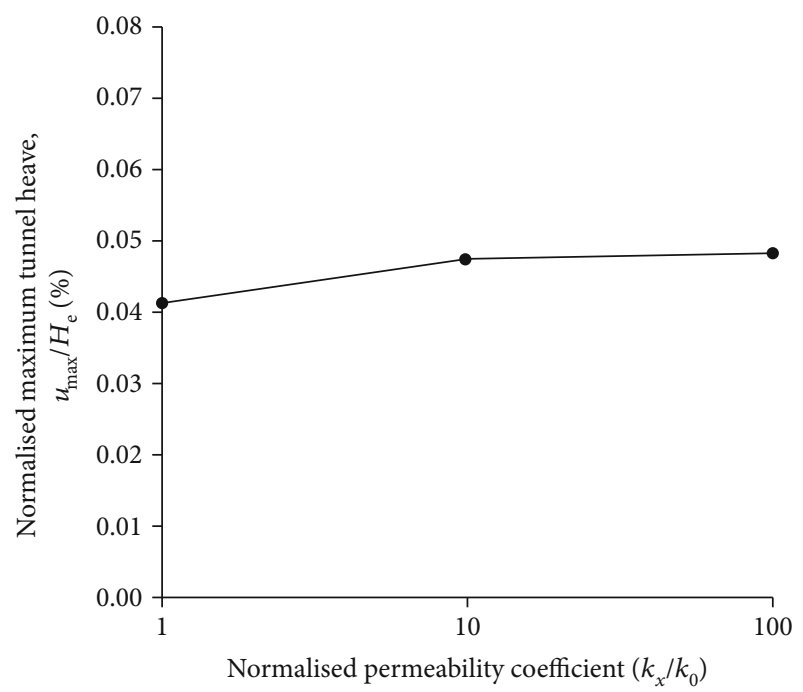

(b)

FIGURE 8: Effect of soil permeability on (a) tunnel heave along its axis and (b) maximum tunnel heave in clay.

the tunnel diameter change gradually increased, but the growth rate slowed down and finally tended toward stability.

Figure 11 shows the variation of the vertical stress change in soil at the tunnel crown with the consolidation time. As can be seen, when the foundation pit excavation was completed, the vertical stress of the soil at tunnel crown decreased owing to stress release, and the maximum variation was approximately $-8 \mathrm{kPa}$. After the completion of the foundation pit excavation, as the consolidation time increased, the effective vertical stress gradually increased, which led to the gradual increase of the tunnel longitudinal uplift, as shown in Figure 9. Additionally, it can be seen that, when the consolidation time was greater than 100 days, the vertical stress changed only slightly, which led to the good stability of the tunnel's longitudinal uplift, as shown in Figure 9. 


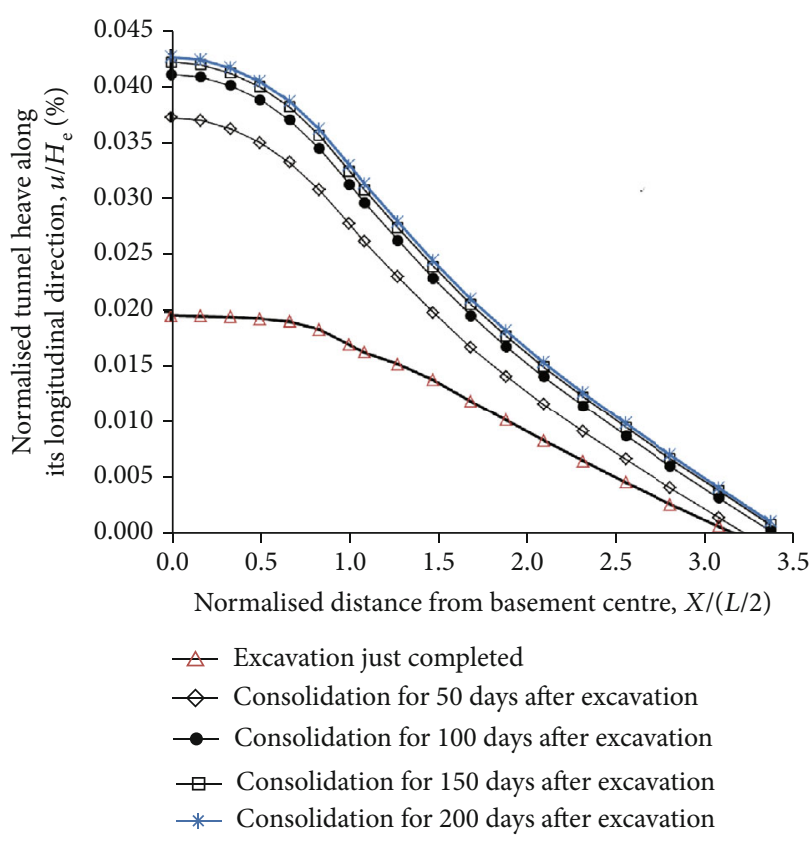

(a)

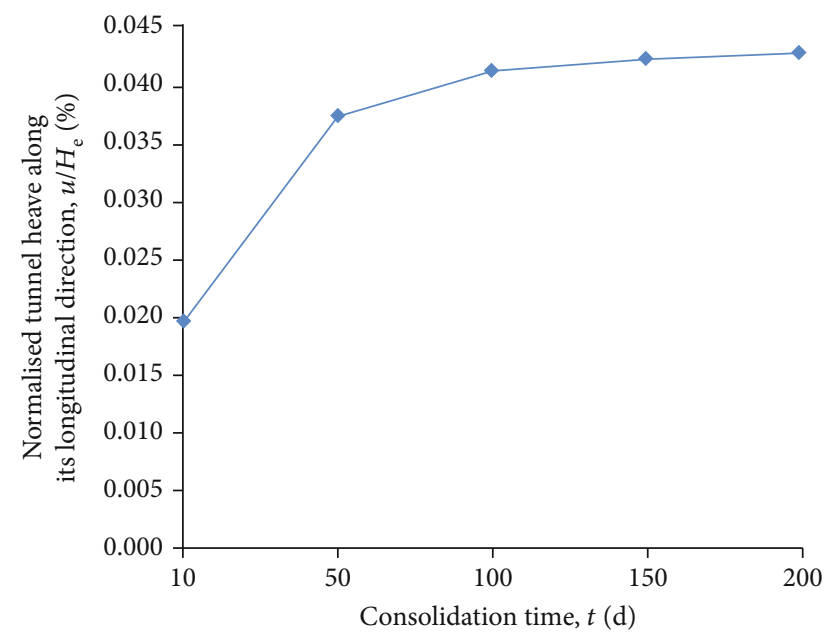

(b)

FIGURE 9: Effect of consolidation time on (a) tunnel heave in longitudinal direction and (b) maximum tunnel heave in clay.

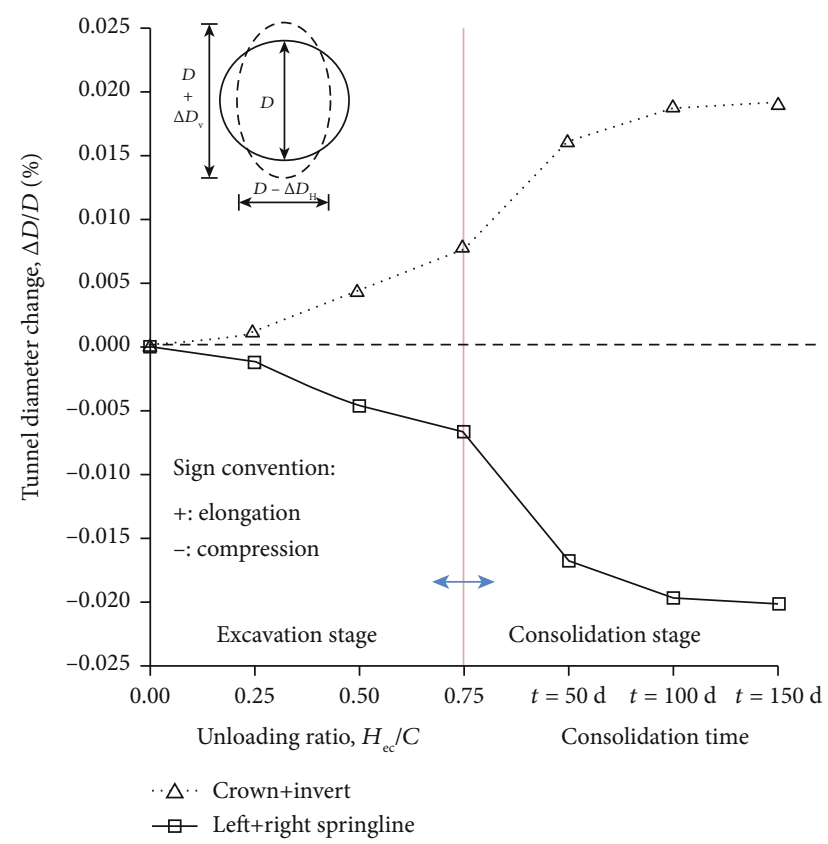

FIGURE 10: Effect of consolidation time on tunnel diameter change in clay.

Figure 12 shows the relationship between the variation of the earth pressure acting at the tunnel lining and the consolidation time. After the foundation pit excavation was completed, as the consolidation time gradually increased, the pore water pressure of the soil around the tunnel gradually dissipated, and the earth pressure acting on the tunnel lining

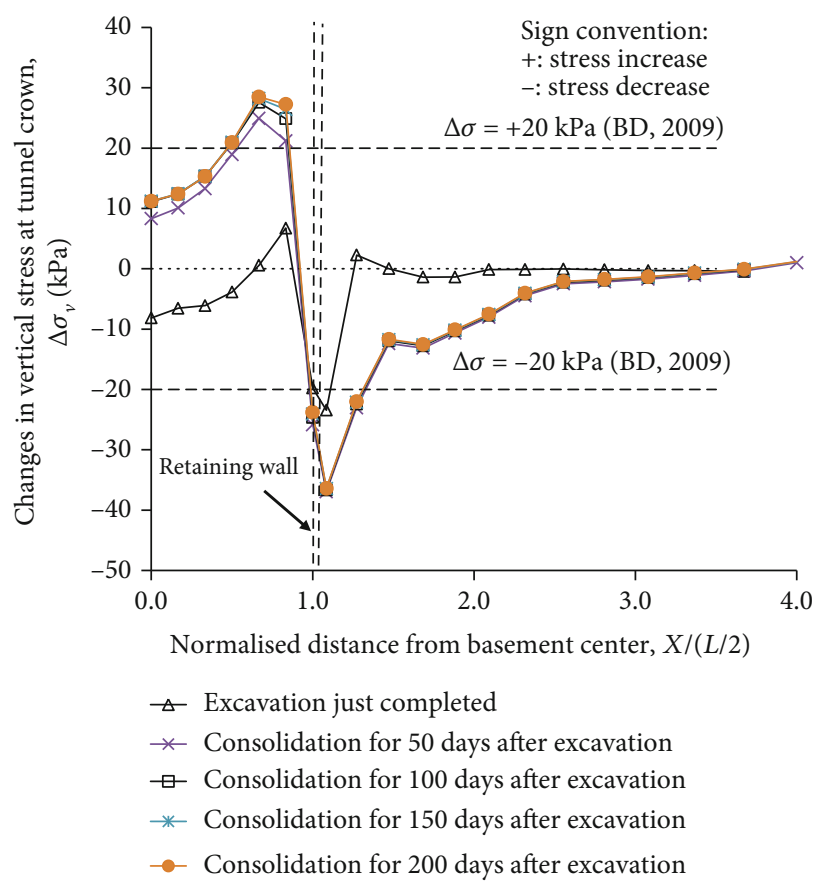

FIgURE 11: Soil vertical stress change at tunnel crown for different consolidation times.

gradually increased, which led to the further increase of the tunnel lining deformation, as shown in Figure 10. When the consolidation time was more than 100 days, the earth pressure acting on the tunnel cross-section did not change much, which led to the good stability of the tunnel crosssection lining deformation, as shown in Figure 10. 


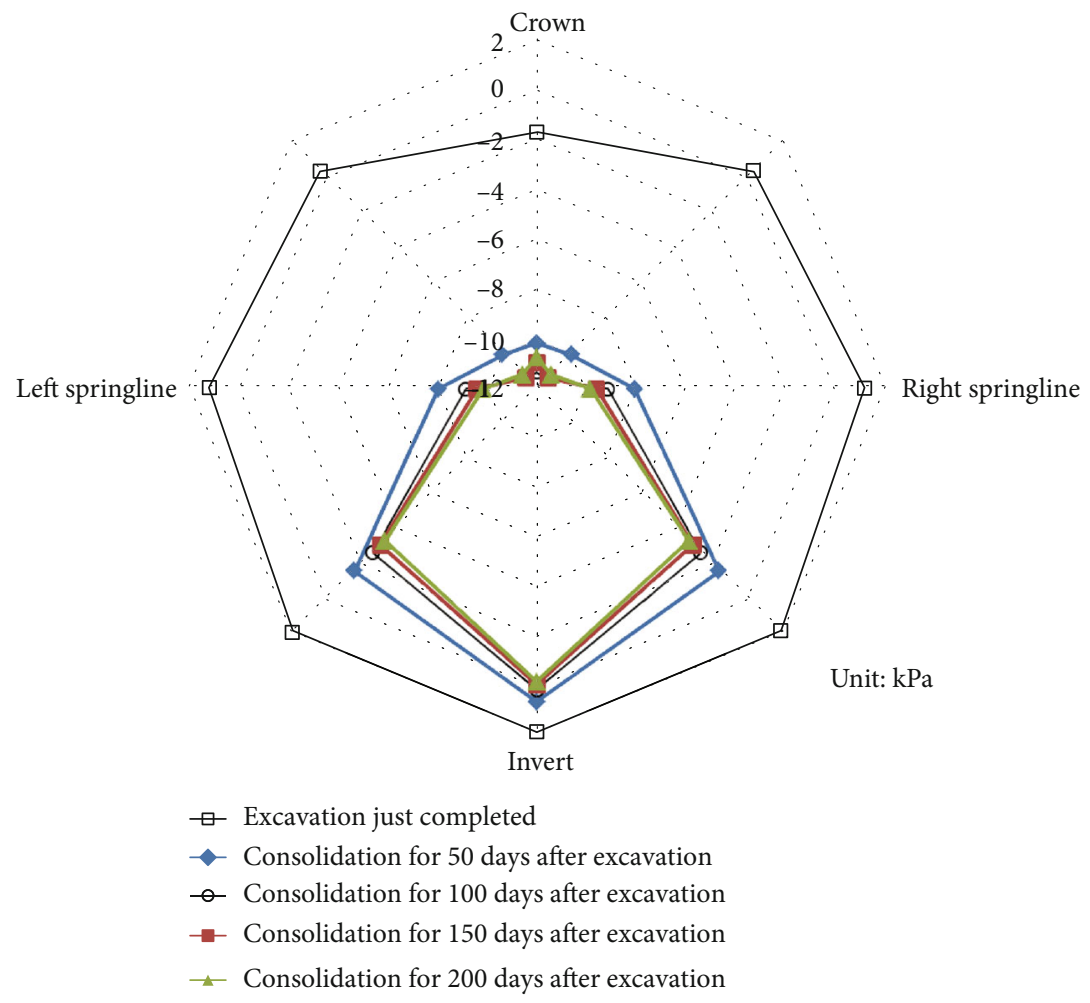

FIGURE 12: Soil pressure change around tunnel lining for different consolidation times.

\section{Conclusions}

Based on the centrifugal model test, this paper investigated the effect of basement excavation on long-term tunnel deformation using the clay hypoplasticity model, which considers the small-strain, stress-path dependence, and soil consolidation characteristics. The influence law and mechanism of the consolidation effect on the long-term deformation caused by excavation were investigated. Numerical parametric investigations were also carried out to study the tunnel response. The main conclusions drawn from this study are summarized as follows:

(a) The unloading of the basement excavation resulted in stress release, which caused tunnel heave. The tunnel heave further increased by approximately two times compared with that observed when the foundation pit excavation had just been completed. The foundation pit excavation directly above the tunnel resulted in the vertical extension and horizontal compression of the tunnel. As the unloading ratio increased, the vertical diameter of the tunnel gradually elongated and the horizontal diameter gradually compressed. Owing to the effect of further consolidation, the tunnel diameter change continuously increased by approximately two times compared with that at the end of the foundation pit excavation. Thus, it is concluded that the consolidation effect has a significant effect on the longitudinal and transverse deformation of the tunnel (b) Owing to the excavation and subsequent consolidation process, the maximum tunnel heave increased with the basement depth, but the growth rate slowed down. Additionally, the maximum tunnel heave decreased linearly with the logarithm of the tunnel lining stiffness. As the consolidation time increased, the longitudinal uplift and tunnel diameter change gradually increased, but the growth rate was slow. When the consolidation time changed from 50 to 150 days, the maximum tunnel heave at the crown and the maximum tunnel diameter change increased by 1.18 and 1.48 times, respectively

(c) As the soil permeability coefficient gradually increased, the tunnel longitudinal uplift and tunnel diameter change gradually increased. When the permeability coefficient of the soil increased by 10 times and 100 times, the maximum uplift of the tunnel increased by $15 \%$ and $17 \%$, and the tunnel diameter change increased by $2 \%$ and $11 \%$. Thus, the soil's permeability coefficient did not have a significant effect on the tunnel heave at the crown nor on the tunnel diameter change

\section{Data Availability}

The computed data used to support the findings of this study are included within the article. 


\section{Conflicts of Interest}

The authors declare that they have no conflicts of interest.

\section{Acknowledgments}

This study was sponsored by the National Natural Science Foundation of China (Grant number 51708245 and Grant number 51904112), the Natural Science Foundation of Jiangsu Province (Grant number BK20160426), and the Natural Science Foundation for Colleges and Universities in Jiangsu Province (19KJA430017). We thank Liwen Bianji, Edanz Editing China (http://www.liwenbianji.cn/ac), for editing the English text of a draft of this manuscript.

\section{References}

[1] D. Burford, "Heave of tunnels beneath the Shell Centre. London, 1959-1986," Géotechnique, vol. 38, no. 1, pp. 135-137, 1988.

[2] C. T. Chang, C. W. Sun, S. Duann, and R. N. Hwang, "Response of a Taipei Rapid Transit System (TRTS) tunnel to adjacent excavation," Tunnelling and Underground Space Technology, vol. 16, no. 3, pp. 151-158, 2001.

[3] B. Liu, D. W. Zhang, C. Yang, and Q. B. Zhang, "Long-term performance of metro tunnels induced by adjacent large deep excavation and protective measures in Nanjing silty clay," Tunnelling and Underground Space Technology, vol. 95, article 103147, 2020.

[4] K. Lo and J. Ramsay, "The effect of construction on existing subway tunnels-a case study from Toronto," Tunnelling and Underground Space Technology, vol. 6, no. 3, pp. 287-297, 1991.

[5] B. Simpson and P. J. Vardanega, "Results of monitoring at the British Library excavation," Proceedings of the Institution of Civil Engineers-Geotechnical Engineering, vol. 167, no. 2, pp. 99-116, 2014.

[6] H. Huang, X. Huang, and D. Zhang, "Centrifuge modelling of deep excavation over existing tunnels," Proceedings of the Institution of Civil Engineers - Geotechnical Engineering, vol. 167, no. 1, pp. 3-18, 2014.

[7] F. Y. Meng, R. P. Chen, S. L. Liu, and H. N. Wu, "Centrifuge modeling of ground and tunnel responses to nearby excavation in soft clay," Journal of Geotechnical and Geoenvironmental Engineering, vol. 147, no. 3, article 04020178, 2021.

[8] C. W. W. Ng, J. W. Shi, and Y. Hong, “Three-dimensional centrifuge modelling of basement excavation effects on an existing tunnel in dry sand," Canadian Geotechnical Journal, vol. 50, no. 8, pp. 874-888, 2013.

[9] C. W. W. Ng, J. W. Shi, D. Mašín, H. S. Sun, and G. H. Lei, "Influence of sand density and retaining wall stiffness on three-dimensional responses of tunnel to basement excavation," Canadian Geotechnical Journal, vol. 52, no. 11, pp. 1811-1829, 2015.

[10] J. W. Shi, C. Ding, C. W. W. Ng, H. Lu, and L. Chen, "Effects of overconsolidation ratio on tunnel responses due to overlying basement excavation in clay," Tunnelling and Underground Space Technology, vol. 97, article 103247, 2020.

[11] M. Doležalová, "Tunnel complex unloaded by a deep excavation," Computers and Geotechnics, vol. 28, no. 6-7, pp. 469493, 2001.
[12] Z. F. Hu, Z. Q. Yue, J. Zhou, and L. G. Tham, "Design and construction of a deep excavation in soft soils adjacent to the shanghai metro tunnels," Canadian Geotechnical Journal, vol. 40, no. 5, pp. 933-948, 2003.

[13] X. Huang, H. F. Schweiger, and H. W. Huang, "Influence of deep excavations on nearby existing tunnels," International Journal of Geomechanics, vol. 13, no. 2, pp. 170-180, 2013.

[14] R. Liang, W. Wu, F. Yu, G. Jiang, and J. Liu, "Simplified method for evaluating shield tunnel deformation due to adjacent excavation," Tunnelling and Underground Space Technology, vol. 71, pp. 94-105, 2018.

[15] H. L. Liu, P. Li, and J. Y. Liu, "Numerical investigation of underlying tunnel heave during a new tunnel construction," Tunnelling and Underground Space Technology, vol. 26, no. 2, pp. 276-283, 2011.

[16] C. W. W. Ng, H. S. Sun, G. H. Lei, J. W. Shi, and D. Mašín, "Ability of three different soil constitutive models to predict a tunnel's response to basement excavation," Canadian Geotechnical Journal, vol. 52, no. 11, pp. 1685-1698, 2015.

[17] J. S. Sharma, A. M. Hefny, J. Zhao, and C. W. Chan, "Effect of large excavation on deformation of adjacent MRT tunnels," Tunnelling and Underground Space Technology, vol. 16, no. 2, pp. 93-98, 2001.

[18] J. W. Shi, C. W. W. Ng, and Y. H. Chen, "Three-dimensional numerical parametric study of the influence of basement excavation on existing tunnel," Computers and Geotechnics, vol. 63, pp. 146-158, 2015.

[19] J. W. Shi, Z. Z. Fu, and W. L. Guo, "Investigation of geometric effects on three-dimensional tunnel deformation mechanisms due to basement excavation," Computers and Geotechnics, vol. 106, pp. 108-116, 2019.

[20] H. S. Sun, Y. D. Chen, J. H. Zhang, and T. S. Kuang, “Analytical investigation of tunnel deformation caused by circular foundation pit excavation," Computers and Geotechnics, vol. 106, pp. 193-198, 2019.

[21] H. S. Sun and W. B. Sun, "Effect of soil reinforcement on tunnel deformation as a result of stress relief," Applied Sciences, vol. 9, no. 7, p. 1420, 2019.

[22] H. S. Sun, L. W. Wang, S. W. Chen, H. W. Deng, and J. H. Zhang, "A precise prediction of tunnel deformation caused by circular foundation pit excavation," Applied Sciences, vol. 9, no. 11, p. 2275, 2019.

[23] H. S. Sun, L. W. Wang, Y. D. Chen, Y. Dong, J. H. Zhang, and W. B. Sun, "Nonlinear analysis of tunnel deformation and mechanisms of stress transfer caused by basement excavation," Soil Mechanics and Foundation Engineering, vol. 55, no. 5, pp. 298-304, 2018.

[24] J. F. Zhang, J. J. Chen, J. H. Wang, and Y. F. Zhu, "Prediction of tunnel displacement induced by adjacent excavation in soft soil," Tunnelling and Underground Space Technology, vol. 36, pp. 24-33, 2013.

[25] Z. Zhang, M. Huang, and W. Wang, "Evaluation of deformation response for adjacent tunnels due to soil unloading in excavation engineering," Tunnelling and Underground Space Technology, vol. 38, pp. 244-253, 2013.

[26] Z. Zhang, M. Zhang, and Q. Zhao, “A simplified analysis for deformation behavior of buried pipelines considering disturbance effects of underground excavation in soft clays," Arabian Journal of Geosciences, vol. 8, no. 10, pp. 7771-7785, 2015.

[27] G. Zheng and S. W. Wei, "Numerical analyses of influence of overlying pit excavation on existing tunnels," Journal of 
Central South University of Technology, vol. 15, Supplementary 2, pp. 69-75, 2008.

[28] Y. Xue, P. G. Ranjith, F. Dang et al., "Analysis of deformation, permeability and energy evolution characteristics of coal mass around borehole after excavation," Natural Resources Research, vol. 29, no. 5, pp. 3159-3177, 2020.

[29] Y. Xue, T. Teng, F. Dang, Z. Ma, S. Wang, and H. Xue, "Productivity analysis of fractured wells in reservoir of hydrogen and carbon based on dual-porosity medium model," International Journal of Hydrogen Energy, vol. 45, no. 39, pp. 20240-20249, 2020.

[30] D. Mašín and I. Herle, "State boundary surface of a hypoplastic model for clays," Computers and Geotechnics, vol. 32, no. 6, pp. 400-410, 2005.

[31] D. Mašín, “A hypoplastic constitutive model for clays," International Journal for Numerical and Analytical Methods in Geomechanics, vol. 29, no. 4, pp. 311-336, 2005.

[32] A. Niemunis and I. Herle, "Hypoplastic model for cohesionless soils with elastic strain range," Mechanics of Cohesive-frictional Materials, vol. 2, no. 4, pp. 279-299, 1997.

[33] J. Najser, D. Mašin, and J. Boháč, "Numerical modelling of lumpy clay landfill," International Journal for Numerical and Analytical Methods in Geomechanics, vol. 36, no. 1, pp. 1735, 2012.

[34] D. Mašín, "A hypoplastic constitutive model for clays with meta-stable structure," Canadian Geotechnical Journal, vol. 44, no. 3, pp. 363-375, 2007.

[35] ABAQUS, Inc, ABAQUS User's and Theory Manuals; Version 6.17, ABAQUS, Inc., Providence Rhode Island, RI, USA, 2017.

[36] D. Mašín, Development and applications of hypoplastic constitutive models [Ph.D. thesis], Charles University in Prague, Zech Republic, 2009.

[37] BD, Practice Note for Authorized Persons APP-24. Technical Notes for Guidance in Assessing the Effects of Civil Engineering Construction/Building Development on Railway Structures and Operations, Building Department of the Government of HKSAR (BD), Hongkong, China, 2009.

[38] G. W. Clough and M. W. Reed, "Measured behavior of braced wall in very soft clay," Journal of Geotechnical Engineering, vol. 110, no. 1, pp. 1-19, 1984.

[39] R. J. Finno, D. K. Atmatzidis, and S. B. Perkins, "Observed performance of a deep excavation in clay," Journal of Geotechnical Engineering, vol. 115, no. 8, pp. 1045-1064, 1989.

[40] BTS, Specification for Tunnelling, Thomas Telford, London, UK, British Tunnelling Society (BTS), 2000. 